Clin Genitourin Cancer. 2012 June ; 10(2): 69-76. doi:10.1016/j.clgc.2012.01.002.

\title{
Prostate cancer stem cells
}

\author{
Shi-Ming Tu, MD ${ }^{1}$ and Sue-Hwa Lin, PhD $^{2}$ \\ ${ }^{1}$ Department of Genitourinary Medical Oncology, The University of Texas MD Anderson Cancer \\ Center, Houston, Texas, USA \\ 2Department of Molecular Pathology, The University of Texas MD Anderson Cancer Center, \\ Houston, Texas, USA
}

\section{Summary}

\begin{abstract}
Stem cells have long been implicated in prostate glandular formation. The prostate undergoes regression after androgen deprivation and regeneration after testosterone replacement.

Regenerative studies suggest that these cells are found in the proximal ducts and basal layer of the prostate. Many characteristics of prostate cancer indicate that it originates from stem cells. For example, the putative $\mathrm{AR}^{-}$status of prostate stem cells renders them inherently insensitive to androgen blockade therapy. The androgen-regulated gene fusion TMPRSS2-ERG could be used to clarify both the cells of origin and the evolution of prostate cancer cells. In this review, we show that the hypothesis that distinct subtypes of cancer result from abnormalities within specific cell types - the stem-cell theory of cancer-may instigate a major paradigm shift in cancer research and therapy. Ultimately, the stem-cell theory of cancers will affect how we practice clinical oncology: our diagnosis, monitoring, and therapy of prostate and other cancers.
\end{abstract}

\section{Introduction}

A key to uncovering the origin of cancer is to identify its cell of origin. Hence, the unspoken appeal of a stem-cell theory of cancers is its focus on the cellular aspects of carcinogenesis. By focusing on the cellular aspects, we advocate a holistic view of cancer-how functional networks, cellular interactions, and microenvironmental factors affect carcinogenesis. This contrasts with a reductionist view of cancer, which emphasizes the molecular aspects, such as genetic aberrations and signaling pathways. We propose that the theory of a stem-cell origin of cancers may be the long-sought unified theory of cancer.

\footnotetext{
(C) 2014 Elsevier Inc. All rights reserved.

Correspondence to: Dr Shi-Ming Tu, Department of Genitourinary Medical Oncology, Unit 1374, 1155 Pressler Street, Houston, TX 77030-3721, USA. Tel.: +1 713-563-7268; Fax: +1 713-745-0827; stu@ mdanderson.org.

Publisher's Disclaimer: This is a PDF file of an unedited manuscript that has been accepted for publication. As a service to our customers we are providing this early version of the manuscript. The manuscript will undergo copyediting, typesetting, and review of the resulting proof before it is published in its final citable form. Please note that during the production process errors may be discovered which could affect the content, and all legal disclaimers that apply to the journal pertain.

Conflicts of interest

The authors declare no conflicts of interest. Proceeds from S-MT's book, "Origin of cancers," are dedicated to cancer research.

Contributors

S-MT wrote the initial draft of the review, and S-HL contributed content and advice; both authors participated in revising the article and approved the final version.
} 
Many biologic phenomena vital for cancer cells are shared by stem cells (figure 1). ${ }^{1}$

Considering how rampantly stem-cell features become manifest during malignant transformation and the way a multitude of embryologic markers and pathways resurface during malignant progression, we should not be surprised that many fundamental biologic processes that are critical for organogenesis, such as epithelial-to-mesenchymal transition and epithelial-stromal interactions, are also important in carcinogenesis.

In this review, we illustrate the biologic ramifications and clinical implications of stem cells in prostatic carcinogenesis and demonstrate that prostate cancer stem cells (CSCs) may be involved in the many facets of prostate cancer. The theory of a stem-cell origin of cancers represents a major paradigm shift that may completely revamp our diagnosis, monitoring, and therapy of prostate cancer.

\section{Prostate stem cells}

Stem cells possess three unique properties: dormancy, self-renewal, and pluripotency. Stem cells have long been implicated in prostate glandular formation. The prostate undergoes regression after androgen deprivation and regeneration after testosterone replacement, ${ }^{2} \mathrm{a}$ cycle that can occur more than 30 times. ${ }^{3}$ Presumably, the cells responsible for this cycling are "immortal" stem cells. Furthermore, these putative prostate stem cells are capable of differentiating into at least three distinct types of prostate cells, namely basal, neuroendocrine (NE), and luminal cells. These three recognized types of prostate cells can be distinguished by their location, cellular markers, and functions.

Basal and NE cells are found in the basal layer of the prostate gland. Basal cells are characterized by expression of high-molecular-weight cytokeratins (CKs) 5 and 14, CD44, integrin $a 6 \beta 1$, and p63. p63 is involved in stem-cell maintenance and differentiation in the normal prostate. ${ }^{4}$ Basal cells also express bcl-2 and c-met, ${ }^{5}$ which mediate cell survival and invasive growth, respectively. Some NE cells express basal-cell CKs, and others co-express prostate-specific antigen (PSA) and chromogranin A, suggesting that these cells arise from local stem cells. ${ }^{6}$ It is unclear whether NE cells are a subset of the basal cell lineage, belong to a unique epithelial lineage, or are a lineage derived from a separate stem-cell population. ${ }^{7}$

Luminal cells are terminally differentiated cells located in the luminal layer of the prostate. This phenotype is characterized by expression of low-molecular-weight CKs 8 and 18, androgen receptor (AR), and PSA.

Central to the idea of prostate stem cells is the existence of intermediate cells. Intermediate cells that express CKs 5, 14, and 18 or CKs 5 and 18 may be cells in transition between basal and luminal cells. ${ }^{8} 9$ For example, Hudson and colleagues ${ }^{10}$ identified a subset of $\mathrm{K} 19^{+}$intermediate cells within both the basal and luminal layers, that may represent basal cells in the process of differentiating into luminal cells. And a rare murine type of intermediate prostate cell co-expresses luminal CK8, AR, and NE markers but not CK5. ${ }^{11}$ Further, prostate stem-cell antigen is considered to be a marker of late intermediate prostate epithelial cells. ${ }^{12}$ 


\section{Stem-cell markers and assays}

The study of prostate stem cells is still in progress. A unique prostate-specific stem-cell marker has not yet been found. However, certain markers of "stemness" that are generally present in various normal and CSCs are also found in prostate stem cells. Among these stemness markers are the $\beta 1$ integrins, CD133, CD44, stem-cell antigen 1 (Sca-1), and the ABCG2-associated drug-resistance proteins.

A decade ago, Collins et al ${ }^{13}$ showed that $\alpha 2 \beta 1^{+}$cells initiated clonogenic growth and prostate acinus-like growth in xenografts. Of note, $\beta 1$ integrin was later found to be crucial for sustaining a functional stem-cell population and establishing asymmetric division in the mammary system. ${ }^{14}$ In addition, $\beta 1$ integrin is required for stem-cell maintenance and positioning of the stem-cell niche (a specialized microenvironment that houses stem cells and is known to affect their development) in Drosophila. ${ }^{15}$

Another stemness marker, CD133 (prominin-1), is expressed in hematopoietic stem and progenitor cells as well as in nonhematopoietic (ie, epithelial and endothelial) stem cells. Fluorescence-activated cell-sorting (FACS) analysis for CD133+ expression is commonly used to isolate and characterize putative stem or progenitor stem cells, the latter of which are relatively more mature stem cells or progenitor cells with stem-cell properties that might be the actual targets of tumorigenic transformation. $\mathrm{CD} 133^{+}$prostate cells display their stemness features by forming prostaspheres and developing prostatic-like acini in immunocompromised male mice. ${ }^{16}$ Subclones of CD133 ${ }^{+}$cells also expressed CK14 or telomerase reverse transcriptase (TERT) and engendered more numerous and larger, branching ducts consisting of basal and luminal cells than did their CD133- counterparts.

CD44 is a cell-surface receptor involved in cell-cell interactions and in cell adhesion and migration. A specialized sialofucosylated glycoform of CD44 functions as a "bone-homing receptor," directing migration of hematopoietic stem cells and mesenchymal stem cells to the bone marrow. Also, a subpopulation of $\mathrm{CD} 44^{+}$prostate cells has been found to preferentially form prostaspheres. ${ }^{17}$

Sca-1 is expressed by stem or progenitor stem cells in various tissues, including hematopoietic, cardiac, mammary, integumentary, muscular, and testicular. In the developing prostate, Sca- $1^{+}$cells are located in the proximal region. ${ }^{18}$ Isolated Sca- $1^{+}$cells are able to regenerate prostatic tubules, ${ }^{19}$ and because the regenerated ducts are clonal and contain both basal and luminal cells, these Sca- $1^{+}$cells are believed to possess stemness features and the capacity for multilineage differentiation. However, the regenerative activity of these cells decreases from generation to generation on serial transplantation, suggesting that most transplanted cells are short-term progenitor cells with limited regeneration potential. ${ }^{20}$

Flow-cytometric separation of a side population of cells is another technique used to identify cells with stem-cell properties. For example, the ATP-binding cassette membrane transporter ABCG2 is associated with multi-drug resistance and stem-cell phenotype. It enables the efflux of Hoechst 33342 dye and the isolation of enriched stem cells from the 
prostate. ${ }^{21}$ These side-population cells develop spheroids and branching structures in threedimensional Matrigel culture.

Note, however, that the markers of stemness just described are definitely not exclusive or even specific for stem cells. Distinct prostate stem or progenitor stem cells are likely to be present in different species, eg, $\mathrm{CD} 44^{+} \alpha 2 \beta 1^{\text {high }}$ in humans and $\mathrm{Lin}^{-} / \mathrm{Sca}-1^{+} / \mathrm{CD} 49 \mathrm{f}^{\text {high }}$ in mice (see table). ${ }^{18,22-35}$ One recent report refuted the utility of CD133 as a potential human or mouse stem-cell marker, ${ }^{36}$ and another indicated that expression of CD133, CD44, or Sca-1 does not correlate with the ability to form prostaspheres or generate prostate glandular structures. ${ }^{30}$ Nevertheless, additional unique stem-cell markers are bound to be discovered.

\section{Location of prostate stem cells}

Where do stem cells reside in the prostate? Regenerative studies suggest that these cells are found in the proximal ducts and basal layer of the prostate. Indeed, studies using stem-cell markers in mice have confirmed that they are localized to these sites.

\section{Proximal ducts}

In the mouse prostate, the regenerative capacity lies in the proximal ducts close to the urethra. ${ }^{20,22,37}$ This region is characterized by abundant smooth muscle cells that secrete high levels of transforming growth factor $\beta$ (TGF- $\beta$ ), a known prostate stem cell-niche factor. ${ }^{22}$ This is also the region within the prostate that contains a high proportion of castrate-resistant $\mathrm{CK}^{+}, \mathrm{Bcl}-2^{+}, \mathrm{Sca}-1^{+}$, and $a 6$ integrin ${ }^{+}$putative stem cells. ${ }^{18-20,29}$ Further evidence that stem cells are located in the proximal ducts comes from experiments showing that $\mathrm{Sca}-1^{+}$cells isolated from this region regenerate prostate tissue more effectively than Sca- $1^{-}$cells from the same region or Sca- $1^{+}$cells from other regions do. ${ }^{18}$

\section{Basal layer}

Because of the preferential survival of basal cells observed after androgen deprivation, the basal layer of the prostate gland is believed to harbor prostate stem cells. ${ }^{3}$ The fact that mice devoid of the basal-cell marker p63 are born without a prostate also supports the basal origin of prostate stem cells. ${ }^{38}$ Further, luminal secretory cells of the prostate arise from p $63^{+}$basal cells. ${ }^{39}$ Recently, Goldstein et al ${ }^{35}$ reported that the basal cell is a potential cell of origin for prostate cancer; an important finding was that the cellular origins of cancer do not necessarily correlate with its histologic features.

However, not all basal cells are stem cells: immunodeficient mice can form and regenerate prostate tissue in the absence of basal cells after implantation of fetal urogenital sinus tissue from p63-null mice. ${ }^{40}$ Therefore, prostate stem cells are likely to be found in the basal layer of the proximal ducts in the prostate, where the stromal cells that constitute the stem-cell niche can support and sustain prostate stem cells even in the absence of basal cells.

\section{The stem-cell niche}

The prostate gland provides a unique opportunity to study the interactions between stem cells and the stem-cell niche, because the epithelial stem cells are easily separated from the 
adjacent urogenital sinus mesenchyme that comprises the embryonic stem-cell niche. ${ }^{41,42}$ By using this approach, Blum et $\mathrm{a}^{28}$ showed that the embryonic prostate stem-cell niche might be similar to the mammalian stem-cell niche in general and that disruption of the stromal-epithelial signaling pathways contributes to oncogenesis.

Similarly, Stevens ${ }^{43}$ was the first to demonstrate that a normal stem cell derived from the genital ridge forms a malignant teratoma when implanted in the vicinity of the testes. Conversely, Mintz and Illmensee ${ }^{44}$ showed that malignant cells obtained from an embryonal carcinoma behave like normal cells when inserted into the body of a blastocyst.

Furthermore, Rous sarcoma virus does not induce sarcomas in chicken embryos, ${ }^{45}$ and B16 murine melanoma cells fail to form tumors after exposure to embryonic niche factors. ${ }^{46}$

Also, when human embryonic cells engineered to produce dopamine were used for treating parkinsonian rats ${ }^{47}$ or to produce insulin for treating diabetic mice, ${ }^{48}$ the treated animals developed an alarming incidence of tumors from these embryonic cells. A very interesting observation in these experiments was that "more-differentiated" stem cells tended to form less-malignant tumors than "less-differentiated" stem cells did.

Together, these findings suggest that the presence of normal stem cells in an aberrant niche is sufficient for the formation of cancer. Whether an aberrant stem cell becomes a cancer cell may also be determined by its niche. The results of these experiments thus confirm the importance of the effects of both the cell of origin and the niche during carcinogenesis.

\section{The prostate onco-niche}

When a stem-cell niche is aberrant, it becomes an onco-niche, a specialized microenvironment that houses cancer cells, just as a stem-cell niche houses stem cells. Therefore, the niche plays a critical role in the final manifestation of both stem cells and cancer cells.

In many respects, the relationship between a stem cell and its niche is also observed in prostate cancer. Zhou et $\mathrm{al}^{23}$ showed that the biologic manifestation of carcinoma could be a consequence of its location. Inactivation of $p 53$ and retinoblastoma $(R b)$ genes in the stem and/or progenitor cells of the proximal prostatic ducts in mice led to the formation of malignant tumors. However, the same genetic defects in lineage-committed transitamplifying and/or differentiated prostate cells in the distal prostatic ducts did not form malignant tumors. Hence, prostatic intraepithelial neoplasia (PIN) that developed in the proximal ducts advanced to carcinoma, whereas PIN that developed in the distal ducts never progressed to carcinoma before the mice died. Of note, when the same experiments were performed in a different cellular context (an ectopic transplantation assay), the mutant cells derived from both the distal and proximal prostatic ducts developed into neoplasms within 3 months.

These observations are consistent with others recently reported by Liao et al, ${ }^{30}$ who demonstrated that cancer-associated fibroblasts are important in the spheroid- and glandforming ability of prostate CSCs. And another study revealed that human prostate cancer samples that expressed high levels of the mesenchymal stem cell marker CD90 were more 
likely to contain cancer-associated fibroblasts and thus might have greater tumor-promoting potential than a subpopulation of low-CD90 expressors has. ${ }^{49}$

Together, the results of these experiments confirm that stromal cells and disruption of stromal-epithelial signaling are integral components of the onco-niche, which in turn plays a critical role in prostate carcinogenesis. In other words, both the right genetic defects and the right onco-niche contribute to the formation of prostate cancer.

\section{Prostate cancer}

Many characteristics of prostate cancer indicate that it originates from stem cells. For example, prostate stem cells express low or negligible levels of androgen receptor $\left(\mathrm{AR}^{-}\right)$ and thus are inherently androgen insensitive compared to the androgen-sensitive $\left(\mathrm{AR}^{+}\right)$ luminal epithelial cells that comprise the bulk of differentiated prostate cancer cells. In addition, the androgen-regulated gene fusion TMPRSS2-ERG could be used to clarify both the cells of origin and the evolution of prostate cancer cells.

\section{Castration resistance}

Androgen blockade therapy is commonly used to reduce the androgen-sensitive ( $\left.\mathrm{AR}^{+}\right)$ luminal epithelial cells that comprise the bulk of differentiated prostate cancer cells. Several investigators have suggested that insensitivity to androgen blockade therapy is an inherited rather than an acquired trait of prostate cancer ${ }^{50-52}$ Furthermore, castration-resistant prostate cancer expresses stem-cell genes within the basal-cell layer. ${ }^{53}$

It is possible that prostate stem cells contribute to castration-resistant prostate cancer. Collins et $\mathrm{a}^{31}$ showed that the primary human prostate cancer cell population with the highest proliferative potential was $\mathrm{AR}^{-}$: it had a stem-cell profile $\left(\mathrm{CD} 44^{+} / \mathrm{\alpha} 2 \beta 1^{\mathrm{high}} / \mathrm{CD} 133^{+}\right)$ and a basal-cell phenotype. The $\mathrm{AR}^{-}$cells were able to regenerate phenotypically mixed populations of nonclonogenic cells, which expressed differentiated cell products, including the AR. The $\mathrm{CD} 44^{+}$tumor-initiating cells from prostate xenograft models were $\mathrm{AR}^{-}$and expressed stemness genes such as OCT3/4, BMII, BETA-CATENIN, and SMOOTHENED. ${ }^{32}$ Importantly, the $\mathrm{CD} 44^{+} \mathrm{AR}^{-}$cells could differentiate into $\mathrm{CD}_{4} 4^{-} \mathrm{AR}^{+}$cells. Likewise, tumor-initiating cells from a clonally derived hTERT-expressing human prostate cancer cell line were $\mathrm{AR}^{-}$and $\mathrm{p} 63-^{-}$, and they also expressed stemness genes, such as OCT4, NANOG, SOX2, NESTIN, CD44, CD133, and $c-K I T .{ }^{54}$ The regenerated tumor contained basal, luminal, and NE-like cells, suggesting that the original clone that had engendered the tumor had had the multilineage-differentiation capacity of a stem cell. It is reasonable to speculate that the $\mathrm{AR}^{-}$prostate stem cells, when present in the tumors, are not affected by the androgen-blockade therapy and remain active in castration-resistant prostate cancer.

AR expression promotes differentiation of prostate epithelial cells. ${ }^{55}$ Indeed, overexpression of AR alone does not induce pathologic growth but reduces the tubule-forming capacity (ie, stemness) of normal prostate stem cells. ${ }^{56}$ It is important to point out that AR function in mesenchymal cells is sufficient for the development of the nascent prostate. ${ }^{57}$ Mesenchymal cells $\left(\mathrm{AR}^{+}\right)$produce growth factors and cytokines, which act on epithelial progenitor cells $\left(\mathrm{AR}^{-}\right)$and affect the latter cells' AR expression and differentiation. Similarly, bone stromal 
cells such as osteoblasts are $\mathrm{AR}^{+58}$ and may produce growth factors and cytokines that affect metastatic prostate $\mathrm{CSCs}$ (putative $\mathrm{AR}^{-}$) in the bone. These findings indicate that mesenchymal cells influence prostate epithelial cells and that the cellular origin of castration-resistant prostate cancer may indeed be inherently $\mathrm{AR}^{-}$.

TMPRSS2-ERG-A fused form of the prostate-specific gene TMPRSS2 with the transcription factor ERG is present in about $50 \%$ of prostate cancers and $20 \%$ of PINs. ${ }^{59}$ If PIN is a premalignant lesion, then the androgen-dependent TMPRSS2-ERG could be a useful biomarker for tracing the evolution of prostate cancer-initiating cells during androgen deprivation and carcinogenesis.

$\mathrm{Yu}$ et $\mathrm{al}^{60}$ found that ERG disrupts AR signaling by binding to and inhibiting AR expression at certain gene-specific loci. Further, ERG directly activates H3K27 methyltransferase EZH2, a polycomb group protein that prevents the affected cell from differentiating (and from AR signaling) and maintains it in a stem-cell-like epigenetic state. Hence, depending on the affected cell of origin, the TMPRSS2-ERG fusion protein may cause maturation arrest in early prostate stem cells or may endow late prostate progenitor or differentiated cells with stemness properties, thereby predisposing them to and propelling them into carcinogenesis. Although both cell types may express the same TMPRSS2-ERG fusion protein, we postulate that they pursue distinct clinical courses because of their different cells of origin.

\section{Prostate cancer stem cells}

If CSCs are derived from normal stem cells, one may be able to purify CSCs by using normal stem-cell markers because the two cell types (ie, cancer and normal stem cells) have certain stem-cell markers in common. This has been shown in several cancer types. Bonnet and Dick ${ }^{61}$ were the first to isolate the so-called CSCs from human acute myeloid leukemia cells with the stem-cell marker CD $34^{+}$and to propagate those cells in immunodeficient mice. Subsequently, subpopulations of CSCs with stem-cell phenotypes have also been demonstrated in breast, ${ }^{62}$ brain, ${ }^{63}$ lung, ${ }^{64}$ and other cancers.

Collins et a ${ }^{31}$ identified putative prostate CSCs from primary human prostate tumors by using the same stem-cell markers $\left(\mathrm{CD} 44^{+} / \mathrm{a} 2 \beta 1^{\mathrm{high}} / \mathrm{CD} 133^{+}\right)$that are used to designate prostate epithelial stem cells. It was interesting that those $\mathrm{CD} 44^{+} / \alpha 2 \beta 1^{\text {high }} / \mathrm{CD} 133^{+}$prostate CSCs displayed a high capacity for self-renewal and for differentiation into $\mathrm{AR}^{+}$cells. Another important discovery showed that a single $\mathrm{Lin}^{-} / \mathrm{Sca}-1^{+} / \mathrm{CD} 133^{+} / \mathrm{CD} 44^{+} / \mathrm{CD} 117^{+}$cell was capable of producing wild-type prostatic acini in the mouse. ${ }^{24}$

In another study, Patrawala et $\mathrm{al}^{32}$ showed that $\mathrm{CD} 44^{+}$prostate cancer cells were intrinsically more tumorigenic and metastatic than their $\mathrm{CD} 44^{-}$counterparts. Also, a fraction of $\mathrm{CD} 44^{+}$prostate cancer cells underwent asymmetric division, which is a hallmark of slowcycling stem cells. ${ }^{32}$ In addition, Hurt et al ${ }^{65}$ showed that CD $44^{+}$LNCaP human prostate cancer cells exhibit stem-cell features, including formation of prostaspheres in cell culture, colonies in soft agar, and tumors in NOD/SCID mice. 
More recently, Kong et $\mathrm{al}^{34}$ demonstrated that prostate cancer cells exhibiting CSC features also expressed an epithelial-to-mesenchymal-transition phenotype. Not only did PC-3 human prostate cancer cells that overexpressed platelet-derived growth factor D show increased clonogenic and prostasphere-forming capacity, which were used to define CSC characteristics, they also lost epithelial markers and gained mesenchymal markers. Moreover, those cells overexpressed numerous stem-cell genes, such as NANOG, OCT4, SOX2, and LIN28B, and activated polycomb repressor complex 2 .

\section{Origin of prostate cancer}

We currently know very little about the origin of prostate cancer-initiating cells. For the longest time, we have focused on the nature of oncogenic changes. But it is equally important for us to identify the cells of origin within which the oncogenic changes occur so that we can validate the actual role of such changes during oncogenesis.

\section{Hierarchy of stem cells versus cancers}

Results from several lines of experimentation support a hierarchical order of stem, progenitor, and differentiated cells within which a particular genetic or epigenetic change or aberration could elicit disparate biologic and clinical phenotypes. For example, Patrawala et $\mathrm{al}^{32}$ discovered a hierarchical order in the tumorigenic potential of human prostate xenograft tumors. In particular, one subpopulation of prostate stem cells $\left(\mathrm{CD} 44^{+} / \mathrm{a} 2 \mathrm{\beta} 1^{+}\right)$was enriched with tumor-initiating cells. Hence, the tumorigenic potential of three human xenograft tumors (DU145, LAPC-4, and LAPC-9) was dependent on their cellular origins in a hierarchical order: $\mathrm{CD} 44^{+} / \mathrm{a} 2 \beta 1^{+/ \text {high }}=\mathrm{CD} 44^{+} / \mathrm{a} 2 \beta 1^{-/ \text {low }}>\mathrm{CD} 44^{-} / \mathrm{a} 2 \beta 1^{+/ \text {high }}>>$ CD44-/a2 $\beta 1^{-/ \text {low }}$.

In another study, Mulholland et $\mathrm{al}^{26}$ isolated LSC ( $\left.\mathrm{Lin}^{-} / \mathrm{Sca}-1^{+} / \mathrm{CD} 49 \mathrm{f}^{\text {high }}\right)$ stem or progenitor stem cells by using FACS in the Pten-null prostate cancer model. Using cells derived from in vitro prostasphere cultures or isolated from primary tumors, they performed in vivo regeneration assays and showed that the LSC subpopulation (as opposed to the more-differentiated luminal subpopulation) comprises basal-like cells that recapitulate the pathology of primary Pten prostate tumors and elicit a preponderance of tumor-initiating activity.

Likewise, prostate tumors arising from luminal cells were consistently less aggressive than those originating from basal stem cells. For example, PSA-driven Pten deletion in prostatic luminal cells resulted only in hyperplasia. ${ }^{25}$ In contrast, probasin-Cre-induced Pten inactivation involving prostatic basal stem cells led to the development of neoplasia. ${ }^{66}$ Similarly, overexpression of AKT1 in Sca- $1^{+}$cells led to the formation of ductal structures containing PIN, whereas its overexpression in Sca- $1^{-}$cells led to predominantly normal ducts. ${ }^{19}$

In addition, by using FACS, Lawson et $\mathrm{al}^{29}$ isolated distinct subpopulations of prostate basal stem cells, luminal cells, and stromal cells. By introducing various oncogenic stimuli (fibroblast growth factor activation, ERG1 expression, PI3K signaling) into these cells, the investigators demonstrated that prostate basal stem cells have a greater capacity (ie, 
efficiency) for cancer initiation than luminal cells do and could produce luminal-like disease. In contrast, prostate luminal cells could not produce basal stem cell-like disease.

\section{Cellular origins of TMPRSS2-ERG}

The stem-cell theory of cancers predicts that the same oncogenic stimuli cause different effects in different cells of origin. Earlier stem cells give rise to tumors that are potentially more heterogeneous and metastatic than the later progenitor cells do (figure 2). ${ }^{1,67}$

The presence of the TMPRSS2-ERG fusion gene may reveal the relevance of a particular oncogenic gene rearrangement depending on the cell types within which it occurs during prostate carcinogenesis. A prospective multicenter study showed that the prevalence of TMPRSS2-ERG was almost 50\% in prostate cancers diagnosed among men who had undergone prostate biopsies. ${ }^{59}$ But TMPRSS2-ERG transcripts were also discovered in benign prostatic hypertrophic or nonmalignant tissues, not just in primary or metastatic prostate cancers. ${ }^{68,69}$ These disparate observations might be attributable to the field-effect phenomenon, although an alternative explanation may be that the type of cell within which a particular oncogenic gene rearrangement occurs is also important for the expression of a malignant phenotype.

We hypothesize that when the cell of origin has more stemness features, the resultant malignancy is potentially more deadly and when it is more differentiated, the resultant malignancy tends to be more indolent. This hypothesis may account for a discrepancy in the reported prognostic significance of TMPRSS2-ERG in prostate cancer when the same genetic aberration develops in different cells of origin. It would explain why TMPRSS2-ERG has been associated with a poor clinical outcome in some studies, ${ }^{70,71}$ but with a better prognosis in others. ${ }^{72,73}$

\section{Diagnosis and prognosis}

The stem-cell theory of cancers predicts that the type of genetic mutation may not be as crucial as the type of cellular target within which the mutation occurs, when it concerns the formation of a particular type of cancer. This novel concept could substantially change the way we predict whether a tumor is lethal or indolent and thus drastically alter the way we diagnose and prognosticate cancer. ${ }^{1}$

The finding that certain aberrant genes (eg, Pten) are present in both hyperplasia and neoplasia suggests that those aberrant genes alone are not sufficient for inducing carcinogenesis. ${ }^{25}$ Similarly, whether inactivation of $p 53$ and $R B$ occurs in a stem and/or progenitor stem cell in the proximal ducts or in a lineage-committed transit-amplifying and/or differentiated cell in the distal ducts may determine the formation of a particular malignant prostate tumor. ${ }^{23}$ Therefore, not only does the aberrant expression of certain genes count, what type of cell and what microenvironment the aberrant expression of these genes occurs in also matters. These animal models reflect a clinical reality in which distinct cancer types arise from different cells of origin with disparate diagnostic and prognostic implications. 


\section{Surrogate end points}

The theory of a stem-cell origin of prostate cancer will also likely influence the way we design clinical trials and monitor response to treatments. For example, certain treatments may be beneficial when they target prostate CSCs, even though the PSA response is modest or lagging. After all, PSA is an androgen-mediated gene. We forewarn that certain treatments that scarcely affect the PSA level but target prostate CSCs would thus be prematurely abandoned unless and until we discover a better surrogate end point for monitoring prostate CSCs.

But how do we know if a treatment is effective when it is affecting prostate CSCs favorably? We have a dilemma when we are treating an asymptomatic patient and the PSA response may be delayed or the radiographic results are indeterminate.

One potential surrogate marker for monitoring the effect of treatment on CSCs is circulating tumor cells (CTCs). CTCs constitute a putative population of CSCs that are already separated from nonmalignant cells in the primary organ or metastatic sites. Because it is plausible that CSCs can differentiate in the circulation just as they do in the primary and metastatic sites, ${ }^{74}$ it is imperative that we discover better ways to identify and isolate those CTCs with stemness features.

\section{Personalized care}

What better way to appreciate the heterogeneity of prostate cancer and discern its different subtypes than to elucidate its cells of origin? The stem-cell theory of prostate cancer is likely to facilitate and expedite the development of personalized treatments that selectively target these subtypes by targeting the specific CSCs and their unique onco-niche and by other means, as follows:

1. The best management option for controlling prostate cancers that are relatively indolent and confined, like a pure ductal or endometrioid adenocarcinoma (ie, a "teratomatous"tumor), is to extirpate them surgically. ${ }^{75}$

2. If one cannot eradicate the tumor by systemic or surgical means, then the next-best option is to keep it as innocuous as possible by using agents that promote differentiation (eg, vitamin D, isoflavones), especially if the mechanism of action underlying the malignant process in the tumor is maturation arrest.

3. Another way to keep the tumor as benign as possible is to render it dormant or quiescent by controlling the onco-niche. In fact, the very idea of an onco-niche suggests that its manipulation has therapeutic implications. Hence, we speculate that abiraterone may attenuate progression of prostate cancer by mitigating the effect of the stromal or bone niche on prostate CSCs (eg, by inhibiting the proliferation or differentiation of osteoblasts). In principle, antiangiogenic and antiinflammatory agents also function in this manner.

4. These therapeutic strategies are most effective in the setting of minimal residual disease after the bulk of differentiated tumor has been eliminated by hormoneablation therapy or chemotherapy. The exposed prostate CSCs can then be treated 
with selected targeted agents (eg, against c-met, ERG) or with differentiationpromoting agents (eg, testosterone) and niche-modulating agents, as just mentioned.

\section{Future directions}

To test the hypothesis that distinct tumor phenotypes arise from unique stem cells in a stemcell hierarchy, we need stem cells. The NHPrE1 spontaneously immortalized prostate progenitor cells and BHPrE1 intermediate cells reported by Jiang et al ${ }^{33}$ may serve this purpose. Of note, NHPrE1 cells express higher levels of the stem-cell markers CD133, CD44, and OCT4 than BHPrE1 cells do. Although both of these human cell lines contain mixed populations (per chromosomal analysis), they do not form colonies in vitro or induce tumorigenicity in vivo. Furthermore, no extrinsic DNA or viral modification is being introduced into these cells. Thus, these cell lines are as "normal" as they possibly can be for the aims of such experiments. A preview of such seminal experiments is already ongoing with the use of homeobox promoter genes in prostate cancer research. ${ }^{26,27}$ Homeobox genes are like stem-cell (ie, embryonic) genes because they regulate lineage differentiation during development. Different homeobox genes imbue different progenitor cells with different "stemness packages" that confer different stem-cell or malignant phenotypes in a hierarchical manner. Hence, prostate basal stem cells (ie, relatively early progenitor stem cells) may contain a certain homeobox gene and become a more heterogeneous or mixed tumor that metastasizes more widely with Pten loss. ${ }^{26}$ On the other hand, castration-resistant Nkx3.1-expressing cells (or CARN cells, which are relatively late progenitor stem cells) are likely to express a more restricted phenotype and become the more conventional prostate acinar adenocarcinoma with the same Pten loss. ${ }^{27}$

\section{Conclusions}

Until now, the notion that cancers arise from specific mutations that occur and accumulate over time has been the groundwork for cancer research and therapy. If proven correct, however, the hypothesis that distinct subtypes of cancer result from abnormalities that occur within specific cell types - the stem-cell theory of cancer-will be a major paradigm shift in research and therapy for prostate and other cancers. This stem-cell theory provides us with a novel frame of reference for better understanding the intricacies of cancer. More important is that it enables us to discover alternative ways to investigate and elucidate the mechanisms underlying cancer. Ultimately, the stem-cell theory of cancers will affect how we practice clinical oncology: our diagnosis, monitoring, and therapy of prostate and other cancers.

\section{Acknowledgments}

Karen F. Phillips, ELS, from the Department of Genitourinary Medical Oncology at MD Anderson Cancer Center, edited the manuscript.

\section{References}

1. Tu, S-M. Origin of cancers: clinical perspectives and implications of a stem-cell theory of cancer. In: Rosen, ST., editor. Cancer treatment and research. Vol. 154. Springer-Verlag; New York, NY: 2010. 
2. Sugimura Y, Cunha GR, Donjacour AA. Morphological and histological study of castration-induced degeneration and androgen-dependent regeneration in the mouse prostate. Biol Reprod. 1986; 34:973-83. [PubMed: 3730489]

3. Isaacs, JT. Control of cell proliferation and cell death in the normal and neoplastic prostate: a stem cell model. In: Rodgers, CH.; Coffey, DS.; Cunha, G.; Grayhack, JT.; Hinman, F., Jr; Horton, R., editors. Benign prostatic hyperplasia. Vol. II. US Department of Health and Human Services; Bethesda, MD, USA: 1987. p. 85-94.a workshop sponsored by the Division of Kidney, Urologic, and Hematologic Diseases of the National Institute of Arthritis, Diabetes, and Digestive and Kidney Diseases, National Institutes of Health, Bethesda, MD, May 16-19, 1986. NIH publication no. 87-2881

4. Grisanzio C, Signoretti S. p63 in prostate biology and pathology. J Cell Biochem. 2008; 103:135468. [PubMed: 17879953]

5. van Leenders GJ, Gage WR, Hicks JL, et al. Intermediate cells in human prostate epithelium are enriched in proliferative inflammatory atrophy. Am J Pathol. 2003; 162:1529-37. [PubMed: 12707036]

6. Bonkhoff H, Remberger K. Differentiation pathways and histogenetic aspects of normal and abnormal prostatic growth: a stem cell model. Prostate. 1996; 28:98-106. [PubMed: 8604398]

7. Abrahamsson PA. Neuroendocrine differentiation in prostatic carcinoma. Prostate. 1999; 39:13548. [PubMed: 10221570]

8. Verhagen APM, Ramaekers FCS, Aalders TW, Schaafsma HE, Debruyne FMJ, Schalken JA. Colocalization of basal and luminal cell-type cytokeratins in human prostate cancer. Cancer Res. 1992; 52:6182-7. [PubMed: 1384957]

9. Xue Y, Smedts F, Debruyne FMJ, de la Rosette JJMCH, Schalken JA. Identification of intermediate cell types by keratin expression in the developing human prostate. Prostate. 1998; 34:292-301. [PubMed: 9496904]

10. Hudson DL, Guy AT, Fry P, O’Hare MJ, Watt FM, Masters JRW. Epithelial cell differentiation pathways in the human prostate: identification of intermediate phenotypes by keratin expression. $\mathrm{J}$ Histochem Cytochem. 2001; 49:271-8. [PubMed: 11156695]

11. Zhou Z, Flesken-Nikitin A, Corney DC, et al. Synergy of p53 and Rb deficiency in a conditional mouse model for metastatic prostate cancer. Cancer Res. 2006; 66:7889-98. [PubMed: 16912162]

12. Tran CP, Lin C, Yamashiro J, Reiter RE. Prostate stem cell antigen is a marker of late intermediate prostate epithelial cells. Mol Cancer Res. 2002; 1:113-21. [PubMed: 12496358]

13. Collins AT, Habib FK, Maitland NJ, Neal DE. Identification and isolation of human prostate epithelial stem cells based on $\alpha_{2} \beta_{1}$-integrin expression. J Cell Sci. 2001; 114:3865-72. [PubMed: 11719553]

14. Taddei I, Deugnier M-A, Faraldo MM, et al. Beta1 integrin deletion from the basal compartment of the mammary epithelium affects stem cells. Nat Cell Biol. 2008; 10:716-22. [PubMed: 18469806]

15. Tanentzapf G, Devenport D, Godt D, Brown NH. Integrin-dependent anchoring of a stem-cell niche. Nat Cell Biol. 2007; 9:1413-8. [PubMed: 17982446]

16. Richardson GD, Robson CN, Lang SH, Neal DE, Maitland NJ, Collins AT. CD133, a novel marker for human prostatic epithelial stem cells. J Cell Sci. 2004; 117:3539-45. [PubMed: 15226377]

17. Garraway IP, Sun W, Tran CP, et al. Human prostate sphere-forming cells represent a subset of basal epithelial cells capable of glandular regeneration in vivo. Prostate. 2010; 70:491-501. [PubMed: 19938015]

18. Burger PE, Xiong X, Coetzee S, et al. Sca-1 expression identifies stem cells in the proximal region of prostatic ducts with high capacity to reconstitute prostatic tissue. Proc Natl Acad Sci USA. 2005; 102:7180-5. [PubMed: 15899981]

19. Xin L, Lawson DA, Witte ON. The Sca-1 cell surface marker enriches for a prostate-regenerating cell subpopulation that can initiate prostate tumorigenesis. Proc Natl Acad Sci USA. 2005; 102:6942-7. [PubMed: 15860580]

20. Goto K, Salm SN, Coetzee S, et al. Proximal prostatic stem cells are programmed to regenerate a proximal-distal ductal axis. Stem Cells. 2006; 24:1859-68. [PubMed: 16644920]

21. Brown MD, Gilmore PE, Hart CA, et al. Characterization of benign and malignant prostate epithelial Hoechst 33342 side populations. Prostate. 2007; 67:1384-96. [PubMed: 17639507] 
22. Salm SN, Burger PE, Coetzee S, Goto K, Moscatelli D, Wilson EL. TGF- $\beta$ maintains dormancy of prostatic stem cells in the proximal region of ducts. J Cell Biol. 2005; 170:81-90. [PubMed: 15983059]

23. Zhou Z, Flesken-Nikitin A, Nikitin AY. Prostate cancer associated with $p 53$ and $R b$ deficiency arises from the stem/progenitor cell-enriched proximal region of prostatic ducts. Cancer Res. 2007; 67:5683-90. [PubMed: 17553900]

24. Leong KG, Wang B-E, Johnson L, Gao W-Q. Generation of a prostate from a single adult stem cell. Nature. 2008; 456:804-8. [PubMed: 18946470]

25. Korsten H, Ziel-van der Made A, Ma X, van der Kwast T, Trapman J. Accumulating progenitor cells in the luminal epithelial cell layer are candidate tumor initiating cells in a Pten knockout mouse prostate cancer model. PLoS One. 2009; 5:e5662. [PubMed: 19461893]

26. Mulholland DJ, Xin L, Morim A, Lawson D, Witte O, Wu H. Lin ${ }^{-} \mathrm{Sca}-1^{+} \mathrm{CD} 49 \mathrm{f}^{\text {high }}$ stem/ progenitors are tumor-initiating cells in the Pten-null prostate cancer model. Cancer Res. 2009; 69:8555-62. [PubMed: 19887604]

27. Wang X, Kruithof-de Julio M, Economides KD, et al. A luminal epithelial stem cell that is a cell of origin for prostate cancer. Nature. 2009; 461:495-500. [PubMed: 19741607]

28. Blum R, Gupta R, Burger PE, et al. Molecular signatures of the primitive prostate stem cell niche reveal novel mesenchymal-epithelial signaling pathways. PLoS One. 2010; 5:e13024. [PubMed: 20941365]

29. Lawson DA, Zong Y, Memarzadeh S, Xin L, Huang J, Witte ON. Basal epithelial stem cells are efficient targets for prostate cancer initiation. Proc Natl Acad Sci USA. 2010; 107:2610-5. [PubMed: 20133806]

30. Liao C-P, Adisetiyo H, Liang M, Roy-Burman P. Cancer-associated fibroblasts enhance the glandforming capability of prostate cancer stem cells. Cancer Res. 2010; 70:7294-303. [PubMed: 20807814]

31. Collins AT, Berry PA, Hyde C, Stower MJ, Maitland NJ. Prospective identification of tumorigenic prostate cancer stem cells. Cancer Res. 2005; 65:10946-51. [PubMed: 16322242]

32. Patrawala L, Calhoun-Davis T, Schneider-Broussard R, Tang DG. Hierarchical organization of prostate cancer cells in xenograft tumors: the $\mathrm{CD} 44^{+} \mathrm{a} 2 \beta 1^{+}$cell population is enriched in tumorinitiating cells. Cancer Res. 2007; 67:6796-805. erratum in: Cancer Res 2007 Sep 15; 67(18): 8973. [PubMed: 17638891]

33. Jiang M, Strand DW, Fernandez S, et al. Functional remodeling of benign human prostatic tissues in vivo by spontaneously immortalized progenitor and intermediate cells. Stem Cells. 2010; 28:344-56. [PubMed: 20020426]

34. Kong D, Banerjee S, Ahmad A, et al. Epithelial to mesenchymal transition is mechanistically linked with stem cell signatures in prostate cancer cells. PLoS One. 2010; 5:e12445. [PubMed: 20805998]

35. Goldstein AS, Huang J, Guo C, Garraway IP, Witte ON. Identification of a cell-of-origin for human prostate cancer. Science. 2010; 329:568-71. [PubMed: 20671189]

36. Missol-Kolka E, Karbanová J, Janich P, et al. Prominin-1 (CD133) is not restricted to stem cells located in the basal compartment of murine and human prostate. Prostate. 2011; 71:254-67. [PubMed: 20717901]

37. Tsujimura A, Koikawa Y, Salm S, et al. Proximal location of mouse prostate epithelial stem cells: a model of prostatic homeostasis. J Cell Biol. 2002; 157:1257-65. [PubMed: 12082083]

38. Signoretti S, Waltregny D, Dilks J, et al. p63 is a prostate basal cell marker and is required for prostate development. Am J Pathol. 2000; 157:1769-75. [PubMed: 11106548]

39. Signoretti S, Pires MM, Lindauer M, et al. p63 regulates commitment to the prostate cell lineage. Proc Natl Acad Sci USA. 2005; 102:11355-60. [PubMed: 16051706]

40. Kurita T, Medina RT, Mills AA, Cunha GR. Role of p63 and basal cells in the prostate. Development. 2004; 131:4955-64. [PubMed: 15371309]

41. Hall JA, Maitland NJ, Stower M, Lang SH. Primary prostate stromal cells modulate the morphology and migration of primary prostate epithelial cells in type 1 collagen gels. Cancer Res. 2002; 62:58-62. [PubMed: 11782359] 
42. Cunha GR, Hayward SW, Wang YZ. Role of stroma in carcinogenesis of the prostate. Differentiation. 2002; 70:473-85. [PubMed: 12492490]

43. Stevens LC. Experimental production of testicular teratomas in mice. Proc Natl Acad Sci USA. 1964; 52:654-61. [PubMed: 14212538]

44. Mintz B, Illmensee K. Normal genetically mosaic mice produced from malignant teratocarcinoma cells. Proc Natl Acad Sci USA. 1975; 72:3585-9. [PubMed: 1059147]

45. Dolberg DS, Bissell MJ. Inability of Rous sarcoma virus to cause sarcomas in the avian embryo. Nature. 1984; 309:552-6. [PubMed: 6203040]

46. Gerschenson M, Graves K, Carson SD, Wells RS, Pierce GB. Regulation of melanoma by the embryonic skin. Proc Natl Acad Sci USA. 1986; 83:7307-10. [PubMed: 3463969]

47. Roy NS, Cleren C, Singh SK, Yang L, Beal MF, Goldman SA. Functional engraftment of human ES cell-derived dopaminergic neurons enriched by coculture with telomerase-immortalized midbrain astrocytes. Nat Med. 2006; 12:1259-68. erratum in: Nat Med 2007 Mar; 13(3): 385. [PubMed: 17057709]

48. Kroon E, Martinson LA, Kadoya K, et al. Pancreatic endoderm derived from human embryonic stem cells generates glucose-responsive insulin-secreting cells in vivo. Nat Biotechnol. 2008; 26:443-52. [PubMed: 18288110]

49. Zhao H, Peehl DM. Tumor-promoting phenotype of CD90hi prostate cancer-associated fibroblasts. Prostate. 2009; 69:991-1000. [PubMed: 19267366]

50. Isaacs JT, Wake N, Coffey DS, Sandberg AA. Genetic instability coupled to clonal selection as a mechanism for tumor progression in the Dunning R-3327 rat prostatic adenocarcinoma system. Cancer Res. 1982; 42:2353-71. [PubMed: 7074614]

51. Gingrich JR, Barrios RJ, Kattan MW, Nahm HS, Finegold MJ, Greenberg MM. Androgenindependent prostate cancer progression in the TRAMP model. Cancer Res. 1997; 57:4687-91. [PubMed: 9354422]

52. Craft N, Chhor C, Tran C, et al. Evidence for clonal outgrowth of androgen-independent prostate cancer cells from androgen-dependent tumors through a two-step process. Cancer Res. 1999; 59:5030-6. [PubMed: 10519419]

53. Bui M, Reiter RE. Stem cell genes in androgen-independent prostate cancer. Cancer Metastasis Rev. 1998-1999; 17:391-9. [PubMed: 10453283]

54. Gu G, Yuan J, Wills M, Kasper S. Prostate cancer cells with stem cell characteristics reconstitute the original human tumor in vivo. Cancer Res. 2007; 67:4807-15. [PubMed: 17510410]

55. Berger R, Febbo PG, Majumder PK, et al. Androgen-induced differentiation and tumorigenicity of human prostate epithelial cells. Cancer Res. 2004; 64:8867-75. [PubMed: 15604246]

56. Xin L, Teitell MA, Lawson DA, Kwon A, Mellinghoff IK, Witte ON. Progression of prostate cancer by synergy of AKT with genotropic and nongenotropic actions of the androgen receptor. Proc Natl Acad Sci USA. 2006; 103:7789-94. [PubMed: 16682621]

57. Cunha GR, Lung B. The possible influence of temporal factors in androgenic responsiveness of urogenital tissue recombinants from wild-type and androgen-insensitive (Tfm) mice. J Exp Zool. 1978; 205:181-93. [PubMed: 681909]

58. Colvard DS, Eriksen EF, Keeting PE, et al. Identification of androgen receptors in normal human osteoblast-like cells. Proc Natl Acad Sci USA. 1989; 86:854-7. [PubMed: 2915981]

59. Mosquera J-M, Mehra R, Regan MM, et al. Prevalence of TMPRSS2-ERG fusion prostate cancer among men undergoing prostate biopsy in the United States. Clin Cancer Res. 2009; 15:4706-11. [PubMed: 19584163]

60. Yu J, Yu J, Mani R-S, et al. An integrated network of androgen receptor, Polycomb, and TMPRSS2-ERG gene fusions in prostate cancer progression. Cancer Cell. 2010; 17:443-54. [PubMed: 20478527]

61. Bonnet D, Dick JE. Human acute myeloid leukemia is organized as a hierarchy that originates from a primitive hematopoetic cell. Nat Med. 1997; 3:730-7. [PubMed: 9212098]

62. Al-Hajj M, Wicha MS, Benito-Hernandez A, Morrison SJ, Clarke MF. Prospective isolation of tumorigenic breast cancer cells. Proc Natl Acad Sci USA. 2003; 100:3983-8. erratum in: Proc Natl Acad Sci USA 2003 May 27; 100(11): 6890. [PubMed: 12629218] 
63. Singh SK, Hawkins C, Clarke ID, et al. Identification of human brain tumour initiating cells. Nature. 2004; 432:396-401. [PubMed: 15549107]

64. Kim CFB, Jackson EL, Woolfenden AE, et al. Identification of bronchioalveolar stem cells in normal lung and lung cancer. Cell. 2005; 121:823-35. [PubMed: 15960971]

65. Hurt EM, Kawasaki BT, Klarmann GJ, Thomas SB, Farrar WL. CD44+ CD24- prostate cells are early cancer progenitor/stem cells that provide a model for patients with poor prognosis. $\mathrm{Br} \mathbf{J}$ Cancer. 2008; 98:756-65. [PubMed: 18268494]

66. Wang S, Garcia AJ, Wu M, Lawson DA, Witte ON, Wu H. Pten deletion leads to the expansion of a prostatic stem/progenitor cell subpopulation and tumor initiation. Proc Natl Acad Sci USA. 2006; 103:1480-5. [PubMed: 16432235]

67. Tu S-M, Lin S-H, Logothetis CJ. Stem-cell origin of metastasis and heterogeneity in solid tumours. Lancet Oncol. 2002; 3:508-13. [PubMed: 12147437]

68. Clark J, Merson S, Jhavar S, et al. Diversity of TMPRSS2-ERG fusion transcripts in the human prostate. Oncogene. 2007; 26:2667-73. [PubMed: 17043636]

69. Watson SK, Woolcock BW, Fee JN, et al. Minimum altered regions in early prostate cancer progression identified by high resolution whole genome tiling path BAC array comparative hybridization. Prostate. 2009; 69:961-75. [PubMed: 19267368]

70. Demichelis F, Fall K, Perner S, et al. TMPRSS2:ERG gene fusion associated with lethal prostate cancer in a watchful waiting cohort. Oncogene. 2007; 26:4596-9. [PubMed: 17237811]

71. Attard G, Clark J, Ambroisine L, et al. Duplication of the fusion of TMPRSS2 to ERG sequences identifies fatal human prostate cancer. Oncogene. 2008; 27:253-63. [PubMed: 17637754]

72. Petrovics G, Liu A, Shaheduzzaman S, et al. Frequent overexpression of ETS-related gene-1 $(E R G 1)$ in prostate cancer transcriptome. Oncogene. 2005; 24:3847-52. [PubMed: 15750627]

73. Saramäki OR, Harjula AE, Martikainen PM, Vessella RL, Tammela TLJ, Visakorpi T. TMPRSS2:ERG fusion identifies a subgroup of prostate cancers with a favorable prognosis. Clin Cancer Res. 2008; 14:3395-400. [PubMed: 18519769]

74. Smirnov DA, Zweitzig DR, Foulk BW, et al. Global gene expression profiling of circulating tumor cells. Cancer Res. 2005; 65:4993-7. [PubMed: 15958538]

75. Tu S-M, Lopez A, Leibovici D, et al. Ductal adenocarcinoma of the prostate: clinical features and implications after local therapy. Cancer. 2009; 115:2872-80. [PubMed: 19402048] 

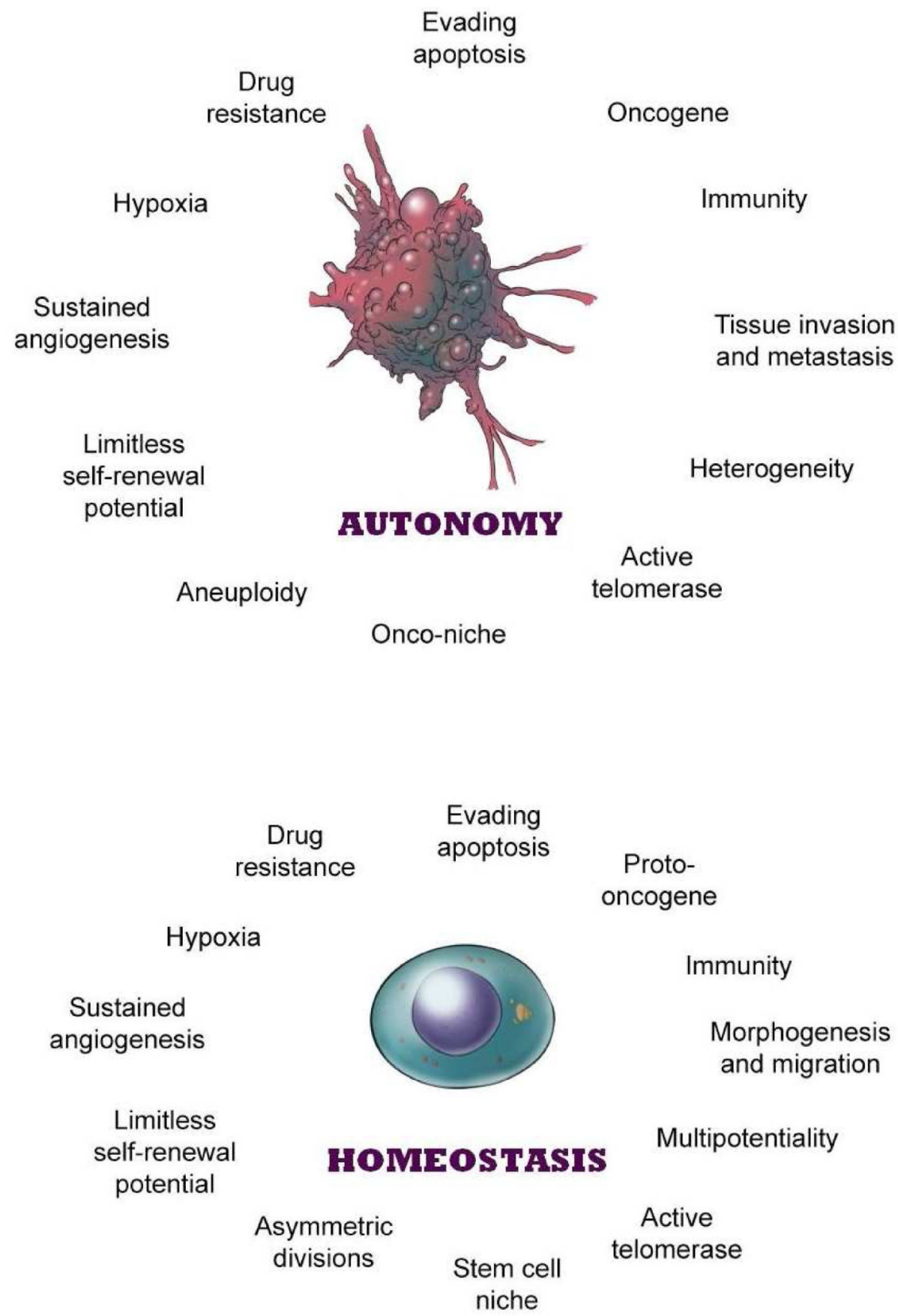

Figure 1. Striking similarities between cancer cells and stem cells

Many of the same essential and relevant characteristics of a cancer cell (top) also happen to comprise the very basic features of a stem cell (bottom). ${ }^{1}$ Reprinted with permission from Springer. 
Cells of origin

Phenotypes

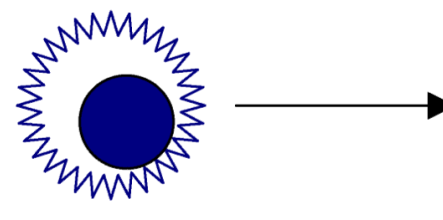

Multipotent progenitor stem cell (a)

Neuroendocrine

Basal

Luminal
More metastatic

More heterogeneous

Fulminant

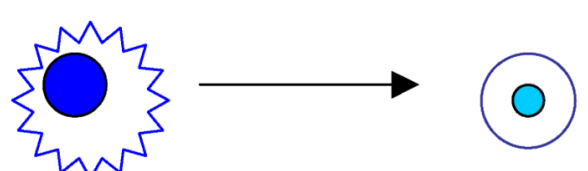

Intermediate progenitor stem cell (b)

Basal

Luminal
Committed progenitor stem cell (c)
Luminal
Less metastatic Less heterogeous Indolent 


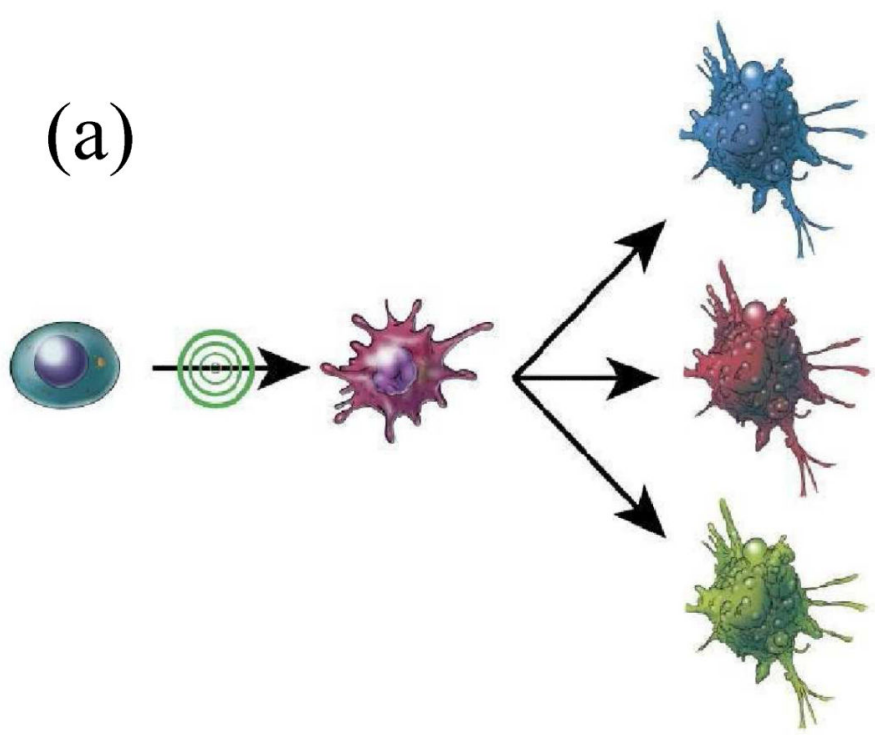

(b)
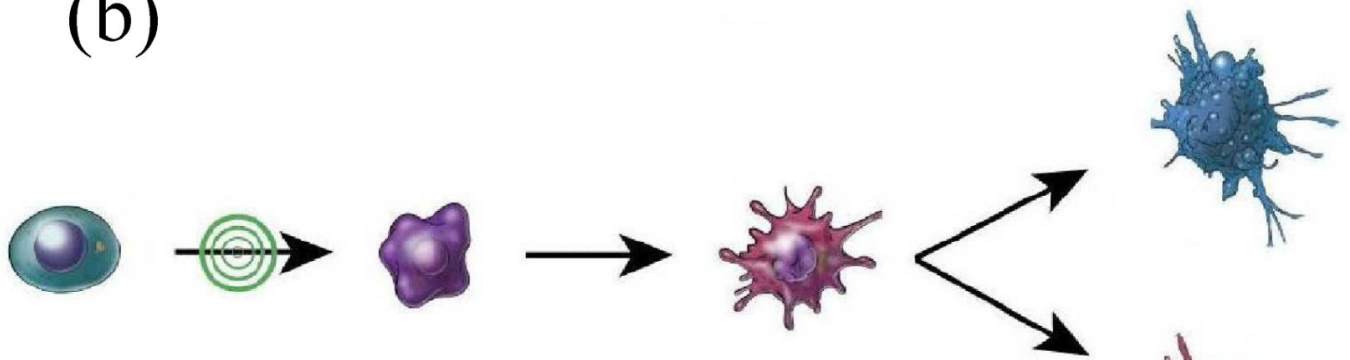

(c)
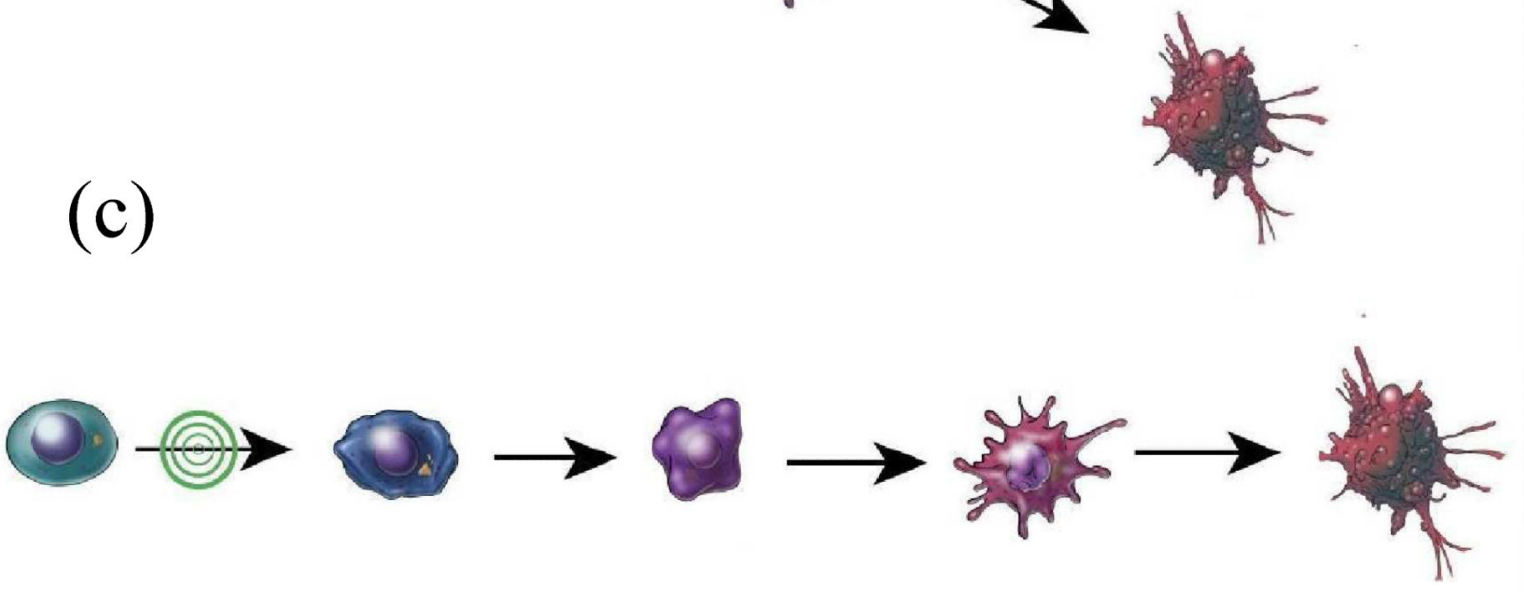

Figure 2. The proposed stem-cell theory of cancer

The proposed theory predicts that tumors arising from earlier stem cells in a stem-cell hierarchy tend to express a more diverse phenotype and pursue a more fulminant clinical course than do those that arise from later progenitor stem cells, which are more inclined to display a more restricted phenotype and follow a more indolent clinical course. Modified with permission from Springer. 
Table

Stem-cell markers in mouse and human models of the prostate and prostate cancer

\begin{tabular}{|c|c|c|}
\hline Investigators & Stem-cell marker & Cell line/model \\
\hline \multicolumn{3}{|l|}{ MOUSE } \\
\hline Salm et al, $2005^{21}$ & $\mathrm{Bcl}-2^{+}$ & \\
\hline Burger et al, $2005^{17}$ & $\mathrm{Sca}^{+} / \mathrm{a}^{+} / \mathrm{Bcl}-2^{+}$ & \\
\hline Zhou et al, $2007^{22}$ & & $\begin{array}{l}\text { Prostate-specific p53 and Rb gene- } \\
\text { deleted mice }\end{array}$ \\
\hline Leong et al, $2008^{23}$ & $\mathrm{Lin}^{-} / \mathrm{Sca}^{+} / \mathrm{CD} 133^{+} / \mathrm{CD} 44^{+} / \mathrm{CD} 117^{+}$ & \\
\hline Korsten et al, $2009^{24}$ & Sca- $1^{+} / \mathrm{Clu}^{+} / \mathrm{Tacstd} 2^{+}$ & PSA-Cre;Pten-loxP/loxP mice \\
\hline Mulholland et al, $2009^{25}$ & $\mathrm{Lin}^{-} / \mathrm{Sca}-1^{+} / \mathrm{CD} 49 \mathrm{f}^{\mathrm{hi}}$ & Pb-Cre;Pten-null mice \\
\hline Wang et al, $2009^{26}$ & & CARNs: Nkx3.1-specific Pten deletion \\
\hline Blum et al, $2010^{27}$ & Wnt, Shh & Fetal and adult prostate stem cells \\
\hline Lawson et al, $2010^{28}$ & $\mathrm{Lin}^{-} / \mathrm{Sca}-1^{+} / \mathrm{CD} 49 \mathrm{f}^{\mathrm{hi}}$ & \\
\hline Liao et al, $2010^{29}$ & $\mathrm{Lin}^{-} / \mathrm{Sca}-1^{+} / \mathrm{CD} 49 \mathrm{f}^{\mathrm{hi}}$ & $\mathrm{cPten}^{-/-}$ \\
\hline \multicolumn{3}{|l|}{ HUMAN } \\
\hline Collins et al, $2005^{30}$ & $\mathrm{CD} 44^{+} / \mathrm{a} 2 \mathrm{~b} 1^{\mathrm{hi}} / \mathrm{CD} 133^{+}$ & Primary tumors \\
\hline Patrawala et al, $2007^{31}$ & $\mathrm{CD} 44^{+} / \mathrm{a} 2 \mathrm{~b} 1^{+}$ & DU145, LAPC4, LAPC9 \\
\hline Jiang et al, $2010^{32}$ & CD133hi/CD $44^{\text {hi }} / \mathrm{OCT} 4^{\text {hi }}$ & NHPrE1 \\
\hline Kong et al, $2010^{33}$ & Nanog/Sox $2 /$ Oct $4 / \operatorname{Lin} 28 B$ & PC3PDGF-D \\
\hline Goldstein et al, $2010^{34}$ & CD49f ${ }^{\text {hi }} /$ Trop $2^{\text {hi }}$ & Primary prostate tissue \\
\hline
\end{tabular}

CARNs $=$ castrate-resistant Nkx3-1-expressing cells; PDGF-D = platelet-derived growth factor D. 